\title{
As fronteiras da pesquisa antropológica: Ética, Autonomia e Tráfico de Órgãos. Um comentário a The Global Traffic in Human Organs, de Nancy Scheper-Hughes
}

\author{
Frontiers of anthropological research: \\ Ethics, Autonomy, and Trafficking in Human \\ Organs. A commentary on The Global Traffic \\ in Human Organs, by Nancy Scheper-Hughes
}

Debora Diniz 1,2

\footnotetext{
${ }^{1}$ Núcleo de Estudos em Ética e Bioética, Universidade Católica de Brasília. QS 07, Lote 1, Brasília, DF 72002-900, Brasil. 2 Anis: Instituto de Bioética, Direitos Humanos e Gênero. C.P. 04554, Brasília, DF 70919-970, Brasil. debdiniz@zaz.com.br
}

\begin{abstract}
The bioethical debate over the commercialization of the human body has intensified in recent years. This article discusses the principles of ethics and autonomy in the most important ethnography on international traffic in human organs, coordinated by anthropologist Nancy Scheper-Hughes. The author discusses how defending the ethics of non-commercialization of the human body entails absolute ethical principles pertaining to human life, a political premise whose legitimacy is not recognized by relativist anthropologists.

Key words Trafficking in Human Organs; Research; Anthropology; Ethics

Resumo O debate sobre os fundamentos éticos da comercialização de partes do corpo humano cresce a cada dia na bioética. Este artigo discute os princípios da ética e da autonomia contidos no mais importante estudo etnográfico sobre o tráfico internacional de órgãos, trabalho coordenado pela antropóloga Nancy Scheper-Hughes. O artigo mostra que a defesa da ética da não-comercialização exige o reconhecimento de fundamentos absolutos e inalienáveis para o ser humano, um pressuposto político cuja legitimidade os antropólogos relativistas resistem em reconhecer. Palavras-chave Tráfico de Órgãos; Pesquisa; Antropologia; Ética
\end{abstract}


A etnografia é ainda o grande instrumento de produção do conhecimento antropológico. É por meio dela que o antropólogo descreve crenças e práticas culturais, ampliando a nossa sensibilidade para a diversidade moral da humanidade. Sejam nas descrições etnográficas de Bronislaw Malinowski sobre os trobiandeses nos anos 20 ou na etnografia de Nancy Scheper-Hughes sobre o tráfico internacional de órgãos, o objetivo e resultado da etnografia ainda se mantêm o mesmo: demonstrar a diversidade moral e cultural da humanidade. Mas, diferentemente de Malinowski e de todos aqueles defensores de uma certa ortodoxia antropológica, o estudo de Scheper-Hughes vai além da mera descrição de práticas sociais, ao introduzir uma perspectiva política e moral de julgamento da diversidade - um exercício do pensamento ético que a antropologia resiste em considerar digno. É exatamente neste casamento inovador entre a etnografia, a antropologia, a ética e os direitos humanos que está a força e as inconsistências da narrativa de Scheper-Hughes.

A autora descreve sua etnografia em termos de uma investigação, antes próxima de uma pesquisa policial e detetivesca, com vistas à denúncia política e ética, que mesmo de um estudo cultural. O universo da pesquisa é o da máfia, o de uma comunidade global que se rege por valores torpes e por uma estrutura indigna, capaz de permitir a mercantilização de partes do corpo humano de pessoas vitimadas pela desigualdade social, segundo valorações apresentadas pela autora, em seu nome e no de seus parceiros de pesquisa da Task-Force Bellagio, grupo que coordena e vem executando a pesquisa em várias partes do mundo. ScheperHughes não economiza adjetivação para descrever seus personagens mafiosos, sejam eles os intermediários na compra e venda de órgãos ou os médicos cirurgiões envolvidos na trama. Em nome dessa intransigência face a alguns dos personagens da etnografia, e especialmente pela opção de julgamento político da prática da mercantilização de partes do corpo humano, a autora confrontou-se com o debate sobre a eticidade ou não do comércio. Muito embora seja notório o mal-estar da narrativa frente a qualquer argumento que sustente a eticidade da comercialização de órgãos humanos, a defesa da repulsa é antes religiosa e circular, que mesmo baseada em argumentos teóricos, sejam eles filosóficos ou antropológicos.

A primeira referência à condição de nãoeticidade da venda e compra de partes do corpo humano foi feita logo no início do texto, onde a autora dizia: “...The organs trade is extensi$v e$, lucrative, explicitly illegal in most countries, and unethical according to every governing body of medical professional life..." (ScheperHughes, 2000:192; sem ênfase no original). Nesta primeira incursão no tema da ética da comercialização, a autora optou pelo uso mais corrente do conceito de ética, isto é, como sinônimo de preceitos normativos de uma determinada classe profissional. Esse uso prescritivo do conceito de ética no campo da regulamentação profissional, apesar de bastante popular, provoca o efeito reverso para quem objetiva ir ao encontro de referenciais inalienáveis para a humanidade por meio da argumentação ética. Seja por um deslize conceitual ou pelo caráter ainda introdutório da discussão no corpo do artigo, não será este o suporte argumentativo que irá sustentar a repulsa à possibilidade de mercantilização ou, como Scheper-Hughes prefere chamar, de comodificação do corpo humano.

Após defender a urgência do debate ético no campo dos estudos antropológicos, a autora avança para o debate bioético, reservando severas e pertinentes críticas a alguns dos referenciais éticos utilizados pelos bioeticistas no trato da questão. Ao rejeitar a hegemonia do princípio da autonomia na bioética, especialmente por seu apelo etnocêntrico euro-americano, a autora lança o argumento que, a meu ver, resume boa parte de suas idéias sobre a não-eticidade da comercialização: “...when concepts such as individual agency and autonomy are invoked in defending the right to sell a spare organ, anthropologists might suggest that certain living things are not legitimate candidates for commodification..." (Scheper-Hughes, 2000:197). Ora, o fato de os antropólogos não considerarem legítima a comodificação de partes do corpo humano, por si só, não é um argumento que fundamente a não-eticidade da transação. Seja qual for a razão, se a sacralidade do corpo humano ou se a inalienabilidade da vitalidade humana como defendem certos autores, o fato é que Scheper-Hughes não permite que seu leitor acompanhe a fundamentação de sua repulsa, uma vez que a mesma se justifica apenas por uma negação da possibilidade de mercantilização do corpo.

Infelizmente, apesar de a discussão ética ser emergente na narrativa de Scheper-Hughes, a autora não conseguiu desenvolvê-la. E isso se deveu basicamente a duas razões. A primeira delas decorre da confusão em que o tema da ética se viu envolvido no decorrer do texto. Não fica claro qual o alvo da discussão ética proposta. O que, de fato, estaria em julgamento para Scheper-Hughes? A ética da pesquisa antropológica, isto é, o ethos profissional do fazer 
antropológico que pressupõe um distanciamento de temas considerados perigosos ou que impliquem em julgamentos valorativos? Ou a ética das transações comerciais em torno do corpo humano? A autora oscila entre os dois conflitos éticos, muito embora não tenha se aprofundado em nenhum dos dois. Grande parte de seus comentaristas da Current Anthropology, muitos deles com formação em antropologia, se ativeram à primeira questão, ou seja, buscaram entender por que argumentos a autora conclamava a urgência do questionamento ético na antropologia e quais as razões dessa restrição disciplinar. A segunda pergunta, no entanto, a que aponta para a questão que considero fundamental no debate sugerido pelo artigo - em que medida é imoral ou mesmo não ético a mercantilização de partes do corpo humano - foi absolutamente desconsiderada por Scheper-Hughes.

Supor a eticidade do princípio da inalienabilidade do corpo humano ou, como prefere a autora, a inalienabilidade de partes consideradas vitais do corpo humano, é também pressupor algum princípio fundamental que justifique a dignidade da integridade corporal, ou seja, considerar alguma qualidade humana como essencial. Explicitar qual seja essa condição essencial do humano que estaria sendo violada com a comodificação do corpo humano deveria ter sido a tarefa inicial, senão básica, para o debate antropológico em torno do tema, ainda mais quando sua autora critica exatamente o pouco relativismo dos bioeticistas. Mas o fato é que eleger e enumerar esse princípio inalienável da dignidade humana que impediria a mercantilização do corpo, seja de partes vitais ou não, tais como óvulos ou sangue, é reconhecer algum princípio universal e, portanto, não relativista de julgamento da questão. Certamente, foi afugentada por esta encruzilhada do pensamento ético que se propõe intervir no mundo real, isto é, a chamada ética prática, que Scheper-Hughes oscilou na argumentação filosófica da não-eticidade da comercialização do corpo humano. Uma vez que quaisquer argumentações baseadas no princípio da sacralidade do corpo humano exigiram pressupostos absolutistas como referência, semelhantes aos utilizados pelos bioeticistas etnocêntricos que criticava, a melhor saída foi, então, anunciar o problema, mas não discuti-lo. Infelizmente, e isso a contragosto da autora, o texto clama por um debate ético, já que o nó da questão reside exatamente na pergunta acerca da (i)moralidade da mercantilização do corpo humano.

O curioso dessa encruzilhada ética do texto foi o fato de que, ao mesmo tempo que a auto- ra criticou severamente os bioeticistas por sua inspiração irrefletida nos pressupostos culturais euro-americanos como sendo válidos para toda a humanidade, o texto também se valeu dos mesmos princípios etnocêntricos para argumentar a imoralidade do usufruto mercantil do corpo. Ao mostrar como o estado chinês vem desconsiderando a dignidade dos sentenciados, considerando-os antes arquivos de órgãos que mesmo seres humanos, a autora apelou para o princípio do consentimento livre e esclarecido, um instrumento bioético de origem estadunidense, como um de seus argumentos fundamentais de defesa: “...since the prisoners are not paid for their 'donation', organs sales per se do not exist in China. However, taking prisoners' organs without consent could be seen as a form of body theft..." (Scheper-Hughes, 2000:196). Ou seja, na impossibilidade de o argumento da imoralidade do comércio de órgãos ser válido para a China, uma vez que o ato da transação inexiste, o suporte foi feito baseando-se no princípio da autonomia, anteriormente criticado. A noção ocidental e contratualista que supõe a autonomia e o indivíduo como valores universais são, em certos contextos, duramente criticados, mas em outros utilizados em defesa da argumentação da autora. $\mathrm{Na}$ verdade, o princípio da autonomia tornouse um verdadeiro fantasma que afugentou e atormentou boa parte das argumentações e discussões éticas do texto.

Ao tentar desdobrar a discussão em torno do princípio da autonomia, uma vez que muitos bioeticistas argumentam a eticidade da mercantilização de partes do corpo humano em nome desse princípio, Scheper-Hughes se viu diante de um verdadeiro embaraço argumentativo. As conseqüências dessa dificuldade de teorização do princípio da autonomia, apesar de não ser exclusiva do artigo, abre flancos perversos de interpretação dos dados, sugerindo, por sua vez, mecanismos ainda mais duros de intervenção social. Em linhas gerais, o que a etnografia demonstrou foi que "...the flow of organs follows the modern routes of capital..." (Scheper-Hughes, 2000:193), ou seja, que o mercado global de órgãos, com seus vendedores e compradores, localiza-se em espaços prédeterminados na estrutura de desigualdade da humanidade: ricos desesperados compram órgãos de pobres desesperados. Na apresentação dessa configuração desigual do comércio, onde não apenas a disparidade econômica é um de seus determinantes, mas também a desigualdade de gênero (as mulheres são as principais doadoras) ou a situação marital das pessoas as tornam mais vulneráveis ao comércio (mulhe- 
res solteiras são preferidas), a autora traça um perfil de absoluta vitimação da identidade para os vendedores e de algozes para os compradores de órgãos. Sua simpatia está de antemão explicitada no artigo: sua voz será de defesa dos interesses e dos direitos dos que vendem seus órgãos, discutindo, portanto, em que grau esta é ou não uma decisão autônoma.

Apesar de concordar com a autora que uma discussão sobre os limites e os fundamentos do princípio da liberdade humana é de extrema importância para a bioética, não tenho dúvidas de que esta seria uma tarefa para um fórum de análise radicalmente diferente do escolhido. O tema da autonomia ou da liberdade exige um cuidado vigilante no trato, pois, na ausência desse respeito temeroso, é possível que o debate se volte contra os interesses das próprias pessoas e grupos a quem se pretende proteger (Diniz \& Guilhem, 1999). Vale acompanhar uma seqüência de trechos, onde ScheperHughes sugere a heteronomia dos oprimidos que vendem órgãos: “...they (the social scientists and human rights activists) are mindful of the social and economic contexts that make the choice to sell a kidney in a urban slum of Calcutta or in a Brazilian favela anything but a free and autonomous one...”; “...exploits the desesperation of the poor, turning their suffering into an opportunity..."; “... are those living under conditions of social insecurity and economic abandonment on the periphery of the new world order really the 'owners' of their bodies..." (Scheper-Hughes, 2000:197). Ou seja, dado que a essência da humanidade é a integridade corporal ou mesmo a manutenção da vitalidade, somente sujeitos desfalcados de sua plena autonomia se disporiam a vender órgãos, segundo propõe a autora.

A dificuldade em aceitar que a pobreza oprime os povos do Terceiro Mundo e, portanto, os tornam heterônomos, não está apenas no fato de que este é um modelo grosseiro de compreensão da liberdade humana, mas principalmente em decorrência das possibilidades inadvertidas que a transposição da fórmula pobreza-opressão-heteronomia pode representar para outros contextos, também políticos de intervenção social. Não tenho dúvidas de que a estrutura global de comércio de órgãos deva ser tal como foi descrita pela etnografia. Mas, infelizmente, essa rede internacional que pressupõe as desigualdades locais como mecanismos de lucro não ocorre apenas para facilitar a comercialização de órgãos. O fato é que a mulher indiana que vende seu rim por dois ou três mil dólares, um montante de dinheiro incalculável para os padrões locais de uma plantadora de chá, onde o salário mensal é de vinte dólares, definitivamente não é heterônoma. No caso dessa mulher, a decisão pela venda de um rim foi fruto de um cálculo de forças, onde de um lado estava ser provedora do prazer britânico pelo chá importado dos campos indianos e de outro um futuro de reduzida sobrevida, com ou sem um rim. Nessa cálculo de possibilidades e ofertas, por mais doloroso que possa parecer, a decisão dessa mulher é completamente autônoma. A estrutura de opressão se mantém: a novidade é que, além da falta do rim, essa mulher não precisa trabalhar como antes nas plantações de chá.

Ora, não quero dizer com isso que seja lícita a venda de órgãos. Não tenho dúvidas do quanto a prática está embebida em relações perversas e residuais da colonização. O que quero apenas chamar a atenção é para o fato de que o apelo ao princípio da autonomia é absolutamente sem sentido neste contexto, seja para justificar a eticidade ou mesmo a imoralidade da comercialização. Essa mulher indiana é livre, autônoma e sabe exatamente o que significa vender um rim. Talvez desconheça detalhes de seu prognóstico, tais como os riscos e índices futuros de desenvolver alguma doença crônica, mas uma certa ignorância faz parte de todo o processo decisório humano. A questão que nos importa, no entanto, não é o grau de lucidez da mulher indiana que vende seus órgãos, mas a tranqüilidade do conforto dos que compram os órgãos, personagens sequer descritos pela etnografia. Scheper-Hughes não confundiu pobreza com heteronomia por acaso. O que a fez considerar as duas categorias em conjunto foi antes o conforto de sua identidade na riqueza que mesmo uma simpatia descompromissada pelas vítimas da opressão que assola a humanidade.

A dificuldade em desenvolver a questão ética e política que se encontra por trás da mercantilização foi tão intensa no artigo que a conclusão resumiu-se ao desenvolvimento da seguinte idéia: “...organ transplantation depends on a social contract and social trust, the grounds for which must be explicit... It also requires a reasonably democratic state in which basic human rights are guaranteed..." (ScheperHughes, 2000:210). Ou seja, do reducionismo ético passamos para um maniqueísmo político, onde a democracia estadunidense, absolutamente incontestável na etnografia, tornou-se a referência não apenas da solução para o tráfico internacional de órgãos, mas principalmente para a cultura dos direitos humanos. Ao tentar escapar do imperialismo inerente às transações comerciais envolvendo o corpo hu- 
mano, a autora recaiu em outro tipo de imperialismo, talvez tão perverso quanto o primeiro: o problema não está nos ricos ingleses ou japoneses que vão à Índia ou à China comprar órgãos, mas no regime hierárquico indiano ou no totalitarismo chinês que disponibiliza e desconhece o valor da vida humana. A democracia é a representação da dignidade humana, uma premissa inabalável da etnografia que não foi questionada.

O problema tornou-se, então, o regime de apartação racial na África do Sul, a intransigência totalitária do governo chinês, os resquícios da ditadura no Brasil, as castas indianas, ou seja, um grupo de países fadados ao atraso humano em nome de políticas indignas. Neste contexto de esquadrinhamento da humanidade, entre vítimas com biografias políticas do atraso e opressores sem biografias políticas, é que se tensionaram as conclusões éticas do artigo de Scheper-Hughes. Curiosamente, no entanto, boa parte dos "canibais", termo pelo qual a autora referencia os compradores de órgãos, são oriundos de países com tradição política democrática, cidadãos do regime político posto como única possibilidade de saída para o dilema da comodificação do corpo humano. A inocência do Primeiro Mundo é tão visível na etnografia, especialmente face à perversão dos países em desenvolvimento, que seria possível dizer que, apesar do olhar antropológico apurado para a diversidade moral da humanidade, a autora foi um tanto quanto etnocêntrica no julgamento ético do problema.

A questão não se resume e não será resolvida por ações políticas locais. Muito provavelmente, intensificar a democracia no Brasil não irá anular a desigualdade existente na relação com os países do Primeiro Mundo. Assim como mostrou a etnografia, a origem do problema é relacional, ou seja, na relação desigual entre povos e nações, onde alguns compram órgãos e vitalidade, e onde outros vendem matériasprimas e prazeres. Sendo assim, qualquer ação, seja no campo das idéias ou da intervenção so- cial, deve considerar o jogo relacional entre os desiguais. É preciso que os compradores e os vendedores de órgãos sejam igualmente apresentados e questionados pela etnografia, uma ausência fundamental do estudo de ScheperHughes, onde apenas as vítimas, descritas pelo olhar denunciatório da repulsa, foram apresentadas. Uma etnografia do comércio internacional de órgãos exige que se apresentem os valores e as crenças dos algozes compradores, que se trace a história da democracia estadunidense ou inglesa, bem como o passado de colonização dessas atuais democracias, onde diferença e desigualdade foram naturalizadas na história e na biografia dos povos oprimidos.

Mas as dificuldades apresentadas no desenrolar do debate devem ser relevadas em nome do pioneirismo da iniciativa, uma vez que Scheper-Hughes e sua equipe da Task-Force Bellagio estão também procurando definir um novo campo de atuação das ciências sociais e da bioética. Outros grupos de movimentos sociais organizados, tais como o movimento feminista, experimentaram processos semelhantes de estruturação do campo disciplinar. A constituição da antropologia ou da bioética de inspiração feminista, por exemplo, são ainda largamente criticadas pelos antropólogos e bioeticistas pouco sensíveis à questão. Mas diferentemente das antropólogas e das bioeticistas feministas que já conquistaram uma consciência política segura dos resultados e objetivos da tarefa - “...feminist anthropology is a justice claim, which demands an ethic of engagement..." (Lynn, 1995:273) -, boa parte das tensões do artigo de Scheper-Hughes decorre exatamente da inexistência de uma definição prévia sobre qual venha ser a qualidade inalienável da humanidade a ser defendida em nome de direitos fundamentais. Qualquer forma de engajamento político dos estudos éticos necessita de uma dose de universalismo, mesmo que estratégico, um recalque do pensamento humanista que os antropólogos relutam em considerar.

\section{Referências}

DINIZ, D. \& GUILHEM, D., 1999. Bioética feminista: O resgate político do conceito de vulnerabilidade. Bioética, 7:181-188.

LYNN, N., 1995. Feminist anthropology? Gender \& Society, 9:272-288.

SCHEPER-HUGHES, N., 2000. The global traffic in human organs. Current Anthropology, 41:191224. 